\title{
Efficacy of Isovolumic Acceleration in Assessing Right Ventricular Function in Pulmonary Hypertension
}

\author{
V. S. Bharathi' ${ }^{1}$ Adikesava Naidu Otikunta1, Y. V. Subbareddy', K. Laxman Rao', \\ Syed Imamuddin ${ }^{1}$, Ashok Thakkar ${ }^{2}$ \\ ${ }^{1}$ Department of Cardiology, Osmania General Hospital, Hyderabad, India \\ ${ }^{2}$ Department of Clinical Trials, Sahajanand Medical Technologies Pvt. Ltd., Surat, India \\ Email: oadikesavanaidu@gmail.com
}

Received 5 April 2014; revised 4 May 2014; accepted 1 June 2014

Copyright (C) 2014 by authors and Scientific Research Publishing Inc.

This work is licensed under the Creative Commons Attribution International License (CC BY).

http://creativecommons.org/licenses/by/4.0/

(c) (i) Open Access

\section{Abstract}

Objective: The aim of the study was to determine usefulness of isovolumic acceleration to assess right ventricular function in patients with pulmonary hypertension. Background: Right ventricular dysfunction is a powerful predictor of adverse outcomes in patients with pulmonary hypertension. Although isovolumic acceleration is a sensitive and relatively load-independent parameter for ventricular contractile function, it has not been widely used. So, the aim of the study was to determine the usefulness of isovolumic acceleration in assessing right ventricular function in patients with pulmonary hypertension. Methods: A single center, prospective observational case-control study has been carried out for the period of one year at Osmania general hospital (Hyderabad). A total of 32 consecutive patients with pulmonary hypertension and 32 age matched healthy controls were recruited in the study as per the inclusion and exclusion criteria of the study. Receiver operator characteristic curves were used to study sensitivity, specificity, positive predictive value, negative predictive values as well as pearson's correlation coefficients. Results: The results of the study showed that isovolumic acceleration has good significant correlation with right ventricular fractional area change $(r=0.554, p=0.001)$ and tissue Doppler myocardial performance index $(r=-0.599, p=0.001)$ whereas a lesser but significant correlation was observed with tricuspid annular plane systolic excursion $(r=0.327, p=0.034)$. Isovolumic acceleration showed higher specificity $(81 \%)$ and positive predictive value $(88 \%)$ in diagnosing right ventricular dysfunction in pulmonary hypertension compared to tricuspid annular systolic excursion velocity and tissue Doppler myocardial performance index parameters. Therefore isovolumic acceleration may be a better variable for diagnosing right ventricular dysfunction. Conclusions: Isovolumic acceleration is a sensitive and specific marker of right ventricular function in pulmonary hypertension.

How to cite this paper: Bharathi, V.S., Otikunta, A.N., Subbareddy, Y.V., Rao, K.L., Imamuddin, S. and Thakkar, A. (2014) Efficacy of Isovolumic Acceleration in Assessing Right Ventricular Function in Pulmonary Hypertension. International Journal of Clinical Medicine, 5, 674-680. http://dx.doi.org/10.4236/ijcm.2014.512093 


\section{Keywords}

\section{Pulmonary Hypertension, Isovolumic Acceleration, Right Ventricular Dysfunction}

\section{Introduction}

The assessment of right ventricular (RV) function is essential in patients with pulmonary hypertension (PH) as $\mathrm{RV}$ dysfunction is a powerful predictor of adverse outcomes. RV failure is the main cause of death in patients with PH. The ability of the RV to adapt to the progressive increase in pulmonary vascular resistance (PVR), which is usually associated with changes in the pulmonary vasculature during $\mathrm{PH}$, is the main determinant of a patient's functional capacity and survival [1]. However, assessment of RV function using conventional methods is often difficult due to the complexity of RV anatomy.

Tissue Doppler echocardiography (TDE) has been used to assess RV global and regional systolic function [2]. Isovolumic acceleration, derived from tissue velocity, is a load-independent measure of contractility and correlates with right ventricular end-systolic elastance [3]. This correlation is less pronounced in clinical studies [4].

Isovolumic acceleration (IVA) is a newer parameter of global RV systolic function. In contrast to tissue Doppler derived peak systolic velocities, strain and strain rate, IVA is more robust and relatively pre-load and after-load independent [5] [6].

Although it appears to be relatively load independent than other methods, its routine use in the assessment of $\mathrm{RV}$ systolic function is not yet recommended as there are no standard reference ranges available. Our study aims to determine the efficacy of IVA in assessing global RV systolic function in patients with PH.

\section{Methods}

\subsection{Study Design}

A single-centred, prospective observational case-control study was carried out at Osmania general hospital between January 2012 and December 2012. The protocol of the study was approved by institutional ethics committee of the hospital before the commencement of the study. Informed consents were obtained from all the patients enrolled in the study. A single-centred, prospective observational case-control study was carried out at Osmania general hospital between January 2012 and December 2012. The protocol of the study was approved by institutional ethics committee of the hospital before the commencement of the study. Informed consents were obtained from all the patients enrolled in the study.

In this study, a total of 32 consecutive patients with PH and 32 age matched healthy people with normal pulmonary arterial systolic pressure (PASP) $<36 \mathrm{~mm}$ of $\mathrm{Hg}$ were included as a control group. We excluded patients with 1) severe tricuspid regurgitation, 2) rhythm other than sinus rhythm, 3) pacemaker lead in the RV, 4) co-existent left heart disease, and 5) right or left bundle branch block.

\subsection{Echocardiographic Evaluation}

All patients underwent tissue Doppler imaging (TDI) using ultrasound equipment (Phillips I E 33, transducer S5.1, $5 \mathrm{~Hz}$ ) with simultaneous electrocardiogram recording. An evaluation of ventricular size and function was performed using standard 2-dimensional echocardiography. Right ventricular end-diastolic area (RVEDA) and end-systolic areas (RVESA) were measured from the two-dimensional apical 4-chamber view in order to calculate right ventricular fractional area change $[R V$ fractional area change $($ RVFAC $)=($ RVEDA - RVESA $) /$ RVEDA $\times 100 \%]$. Right ventricular systolic pressure (RVSP) or systolic pulmonary arterial pressure (SPAP) was calculated with the tricuspid regurgitation (TR) jet velocities. Mean pulmonary arterial pressure (MPAP) and pulmonary arterial diastolic pressure (PADP) were estimated from the end-diastolic pulmonary regurgitation velocity. The myocardial performance index (MPI) or Tei index, also known as right ventricular index of myocardial performance is defined as the ratio of the isovolumic time and the ejection time (ET). It was obtained from two methods: the pulsed Doppler method (d-MPI) and the tissue Doppler method (t-MPI). Tricuspid annular plane systolic excursion (TAPSE) was acquired by placing an M-mode cursor through the tricuspid annulus from a standard apical 4-chamber view. Tricuspid annular systolic excursion velocity (Sm) was measured by TDI in the 
apical 4-chamber view. The RV IVA during isovolumic contraction is defined as the peak isovolumic myocardial velocity (IVV) divided by time to peak velocity and was typically measured for the RV by Doppler tissue imaging at the lateral tricuspid annulus.

\subsection{Statistical Analysis}

Statistical analysis was conducted using Statistical Package for Social Sciences (SPSS) version 20.0 (SPSS, inc., Chicago, IL, USA). Statistical significance was defined as $\mathrm{p}<0.05$. Descriptive data for continuous variables are expressed as mean \pm standard deviation. Pearson's correlation coefficients were calculated to analyse the association of echocardiographic parameters. Sensitivity, specificity, positive predictive value and negative predictive values of the IVA, Sm, and TAPSE variables are calculated using receiver operator characteristic (ROC) curves.

\section{Results}

Among $32 \mathrm{PH}$ patients enrolled with majority of women (60\% women, mean age 38.4 years, mean PASP: 76.1 $\pm 19.4 \mathrm{mmHg}$ ), there were 9 patients with idiopathic pulmonary arterial hypertension, 4 patients with Eisenmengers syndrome, 3 patients with left to right shunts, 13 patients were diagnosed with lung diseases, 1 patient with extra-hepatic portal hypertension, and 2 patients with Human Immunodeficiency Virus-positive.

Echocardiographic parameters in patients with PH and control group were described in Table 1. IVA, which is a measure of global RV systolic function, was found to be significantly different in PH patients (2.71 \pm 1.1$)$ and in controls $(3.71 \pm 0.61$ ). The echocardiographic parameters such as t-MPI, RVFAC, Sm, TAPSE also showed significant difference between two groups.

ROC curve was analyzed to determine the specificity and sensitivity of parameters in two diagnostic groups (diseased/normal). All the three variables (Sm, t-MPI, IVA), were tested for sensitivity, specificity, positive predictive value and negative predictive value by ROC curve which has been depicted in Figures 1(a)-(c) respectively.

Among the PH patients, the higher specificity (81\%) and positive predictive value $(88 \%)$ was observed in IVA as compared to Sm and t-MPI parameters (Table 2). Therefore IVA may be a better variable for diagnosing RV dysfunction.

We had correlated IVA with established RV systolic function parameters, RVFAC and t-MPI as well as with TAPSE using Pearson's correlation coefficient (Table 3).

Table 1. The baseline data and echocardiographic characteristics of right ventricular systolic dysfunction of the study population.

\begin{tabular}{cccc}
\hline Characteristics & PH Group $\mathrm{N}=32$ & Control Group $\mathrm{N}=20$ & p-value \\
\hline Age, years (mean \pm SD) & $38.4 \pm 11.21$ & $33 \pm 10.7$ & - \\
Heart rate, (bpm) (mean \pm SD) & $82.3 \pm 6.7$ & $76.9 \pm 4.42$ & - \\
Gender Male, $\mathrm{n}(\%)$ & $12(37.5)$ & $10(50)$ & $<0.01$ \\
RVS, (mmHg) (mean \pm SD) & $76.1 \pm 19.4$ & $25.33 \pm 3.67$ & $<0.01$ \\
t-MPI (mean \pm SD) & $0.6 \pm 0.26$ & $0.34 \pm 0.077$ & $<0.01$ \\
Sm, (cm/sec) & $11.9 \pm 2.35$ & $39.15 \pm 10.94$ & $<0.01$ \\
IVRT, (mean \pm SD) & $73.34 \pm 26.33$ & $2.24 \pm 0.31$ & $<0.01$ \\
TAPSE, (mean \pm SD) & $1.83 \pm 0.622$ & $3.71 \pm 0.61$ & $<0.01$ \\
IVA, (mean \pm SD) & $2.71 \pm 1.1$ & $49.15 \pm 3.85$ & $<0.01$ \\
RVF, (mean \pm SD) & $35.59 \pm 8.84$ & $<$
\end{tabular}

RVS: Right ventricular systolic function, t-MPI: Tissue Doppler-myocardial performance index, Sm: Tricuspid systolic annular velocity, IVRT: Intraventricular relaxation time, TAPSE: Tricuspid annular plane systolic excursion, IVA: Isovolumic acceleration, RVF: Right ventricular fraction area change. 


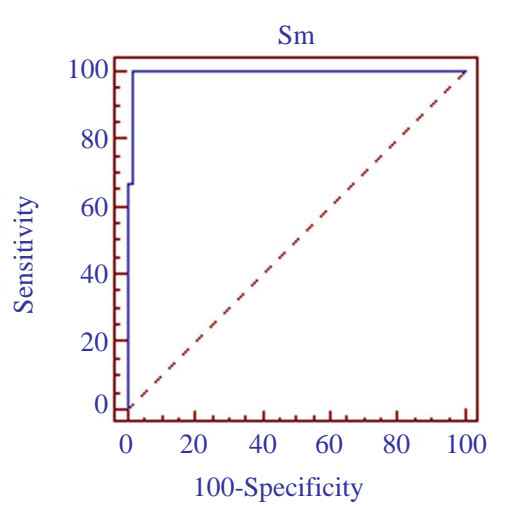

(a)

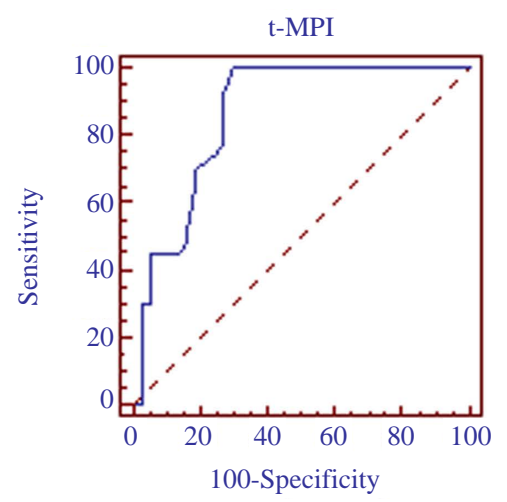

(b)

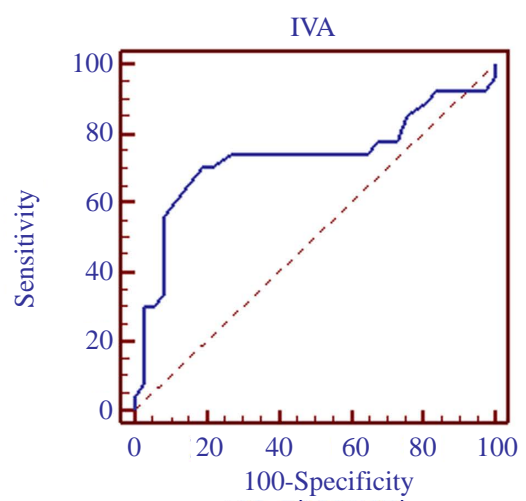

(c)

Figure 1. Receiver operator characteristic curves of: (a) Tricuspid annular systolic excursion velocity (Sm); (b) Tissue Doppler myocardial performance index (t-MPI); (c) Isovolumic acceleration (IVA) to diagnose right ventricular dysfunction.

Table 2. Comparison of sensitivity, specificity, positive and negative predictive valves of isovolumic acceleration, tricuspid annular systolic excursion velocity and tissue Doppler myocardial performance index.

\begin{tabular}{cccccccc}
\hline Variable & $\begin{array}{c}\text { Cut-off } \\
\text { Value }\end{array}$ & AUC & p value & $\begin{array}{c}\text { Sensitivity } \\
\mathbf{( \% )}\end{array}$ & $\begin{array}{c}\text { Specificity } \\
(\mathbf{\%})\end{array}$ & $\begin{array}{c}\text { Positive Predictive } \\
\text { Value (\%) }\end{array}$ & $\begin{array}{c}\text { Negative Predictive } \\
\text { Value (\%) }\end{array}$ \\
\hline Sm & $\leq 11.8$ & 0.705 & $<0.01$ & 74.10 & 62.20 & 64.70 & 66.66 \\
t-MPI & $>0.37$ & 0.861 & $<0.01$ & 100 & 70.3 & 81.57 & 96.15 \\
IVA & $\leq 3$ & 0.731 & $<0.01$ & 70.40 & 81.10 & 88.46 & 76.31 \\
\hline
\end{tabular}

IVA-Isovolumic acceleration; Sm—Tricuspid annular systolic excursion velocity and t-MPI—tissue Doppler myocardial performance index.

Table 3. Correlation between isovolumic acceleration and other echocardiographic parameters.

\begin{tabular}{lccc}
\hline IVA & t-MPI & RVFAC & TAPSE \\
\hline Pearson's correlation coefficient & 0.599 & 0.554 & 0.327 \\
Sig (1-tail) & $0.001^{*}$ & $0.001^{*}$ & $0.034^{* *}$
\end{tabular}

${ }^{*}$ Correlation is significant at 0.01 levels; ${ }^{* *}$ Correlation is significant at 0.05 levels; IVA-Isovolumic acceleration; t-MPI-tissue Doppler myocardial performance index; RVFAC—Right ventricular fractional area change; TAPSE-Tricuspid annular plane systolic excursion.

It was found that IVA has good correlation with RVFAC $(\mathrm{r}=0.554, \mathrm{p}=0.001)$ [Figure 2(a)] and t-MPI ( $\mathrm{r}=$ $-0.599, \mathrm{p}=0.001)$ [Figure 2(b)] whereas a lesser but significant correlation was observed with TAPSE ( $\mathrm{r}=$ 0.327, $\mathrm{p}=0.034)$.

\section{Discussion}

Being less muscular, more thin walled, compliant, and less frequently or obviously involved than the left ventricle in diseases such as myocardial ischemia, cardiomyopathy, or valvulopathy, the RV has generally been considered a victim of pathological processes affecting the cardiovascular system [7].

The function and size of the RV are not only indicators of the severity and chronicity of PH but impose an additional cause of symptoms. RV function is the most important determinant of longevity in patients with PAH [1] [8]-[10]. So the parameters which have to be reported includes a measure of right ventricular size, right atrial (RA) size, SPAP, PADP, along with an assessment of RV systolic function. Several echocardiographic parameters have been reported to assess the RV function, namely, MPI, TAPSE, 2D RV FAC, 2D RV EF, TDI, ratio of RV transverse diameter to left ventricular transverse diameter (RVETD/LVETD), IVA and Sm. Other than echocardiography, cardiac magnetic resonance (CMR) and right heart catheterization can be performed for the diagnosis of PAH.

MPI provides an index of global RV function in which MPI $>0.40$ by pulsed Doppler and $>0.55$ by tissue Doppler indicates RV dysfunction. But pulsed Doppler MPI is unreliable when RV ET and TR time are measured 


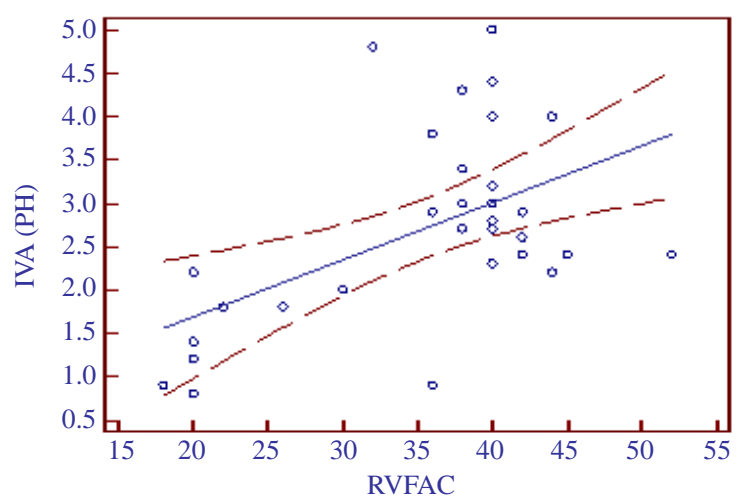

(a)

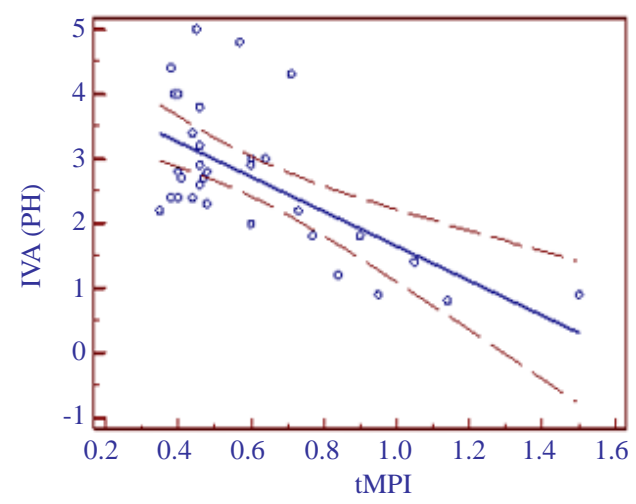

(b)

Figure 2. Correlation of isovolumic acceleration (IVA) with: (a) Right ventricular fractional area change (RVFAC); (b) Tissue Doppler myocardial performance index (t-MPI).

with differing R-R intervals, as in atrial fibrillation. Moreover, it is load dependent and unreliable when RA pressure is elevated [11]. In our study, the MPI values were found to be $0.48 \pm 0.23$ by pulsed Doppler and 0.60 \pm 0.26 by tissue Doppler, which clearly indicates RV dysfunction in PH group.

Both TAPSE and Sm reflect the longitudinal systolic function of the RV. Although TAPSE is simple, less dependent on optimal image quality and reproducible, but it is angle dependent. It also assumes that the displacement of a single segment represents the function of a complex 3D structure. Sm is also angle dependant and assumes that the function of a single segment represents function of the entire RV which is not likely in conditions that include regionality, such as RV infarction or pulmonary embolism.

The rate of pressure rise in the ventricles $(\mathrm{dP} / \mathrm{dt})$ is evaluated and validated as an index of systolic function. But because of the lack of data in normal subjects and in pathologic conditions, as well as being load dependent, $\mathrm{RV} \mathrm{dP/dt} \mathrm{cannot} \mathrm{be} \mathrm{recommended} \mathrm{for} \mathrm{routine} \mathrm{uses.}$

Strain and strain rate values have been studied in a number of conditions affecting the right heart, and found to have close correlation with myocardial contractility in in-vitro and in-vivo experimental settings. But one dimensional strain is not a method of choice because it is angle dependent and has a poor signal-to-noise ratio. Two dimensional strains is not angle dependant and possesses an improved signal to noise ratio, but, strain and strain rate is a complex measure with a high degree of variability that requires additional software and offline analysis. Finally, because of lack of reproducibility and paucity of data this technique is not recommended for routine clinical use.

RV IVA is a relatively load independent measure of global RV systolic function that has been shown to correlate with severity of illness in conditions affecting right heart function. It is an angle dependent Doppler measurement that appears to vary with age and heart rate. Because of the broad confidence interval around its lower reference limit ( $2.2 \mathrm{~m} / \mathrm{s}^{2}$ with a broad $95 \%$ confidence interval of 1.4 to 3.0$)$, no reference value can be recommended [11].

Several studies have shown that the small changes in contractile function can be detected by measuring IVA while changes in the preload and afterload within the physiological range did not affect this parameter. In contrast to tissue Doppler derived peak systolic velocities, strain and strain rate, IVA is most robust and relatively pre and after load independent [5] [6].

In earlier clinical studies, it was shown that IVA measured at the level of the RV tricuspid annulus detects reduced RV systolic function in relation to the degree of pulmonary regurgitation in patients after repair of tetrology of fallot [12]. TDI derived IVA has been used to assess a reduction in functional reserve of both ventricles in patients after atrial repair of dextro-position of the great arteries [13].

IVA is also a reliable, non-invasive parameter to assess the positive effect of continuous positive airway pressure (CPAP) therapy in patients with obstructive sleep apnea syndrome on right ventricular systolic function [14]. It may be used for the early detection of right ventricular systolic dysfunction in patients with mitral stenosis without signs of systemic venous congestion [15].

Like all Doppler measurements, IVA is angle dependent. Furthermore, IVA is age dependent. The highest IVA will be found in the $2^{\text {nd }}$ decade of life, with a progressive decline of IVA in each following decade [16]. 
IVA correlates closely with invasively derived hemodynamic indices of contractility, such as dp/dt and end systolic elasticity [17].

It is well known that there may be regional heterogeneity in RV function. Dambruskaite et al. [18] have shown that in patients with pulmonary arterial hypertension, the regional function will first exhibit depression in the smooth inlet portion of the RV. In this setting, regional analysis of myocardial function may enable the early diagnosis of imminent $\mathrm{RV}$ failure before irreversible damage may occur.

Our study also found a good correlation of IVA with t-MPI and RV FAC and a lesser but significant correlation with TAPSE.

The limitations were:

1) Cardiac catheterisation was not done to assess the pulmonary artery pressures.

2) Cardiac magnetic resonance was not used as a comparator for the estimation of RV function.

3) We did not use angle correction for the measurement of either TDI or pulsed Doppler as we do not consider that this is a major source of error since we were measuring time intervals that are minimally affected by angle of incidence.

\section{Conclusion}

IVA has a good sensitivity and a higher specificity and positive predictive value than Sm and t-MPI in assessing right ventricular function in patients with PH. Therefore IVA can be considered as a better variable for diagnosing RV dysfunction.

\section{Acknowledgements}

We are thankful to Dr.SAA and Latheef for the statistical support.

\section{References}

[1] Chin, K.M., Kim, N.H. and Rubin, L.J. (2005) The Right Ventricle in Pulmonary Hypertension. Coronary Artery Disease, 16, 13-18. http://dx.doi.org/10.1097/00019501-200502000-00003

[2] Galie, N., Hoeper, M.M., Humbert, M., Torbicki, A., Vachiery, J.L., Barbera, J.A., Beghetti, M., Corris, P., Gaine, S., Gibbs, J.S., Gomez-Sanchez, M.A., Jondeau, G., Klepetko, W., Opitz, C., Peacock, A., Rubin, L., Zellweger, M. and Simonneau, G. (2009) Guidelines for the Diagnosis and Treatment of Pulmonary Hypertension: The Task Force for the Diagnosis and Treatment of Pulmonary Hypertension of the European Society of Cardiology (Esc) and the European Respiratory Society (Ers), Endorsed by the International Society of Heart and Lung Transplantation (Ishlt). European Heart Journal, 30, 2493-2537. http://dx.doi.org/10.1093/eurheartj/ehp297

[3] Vogel, M., Schmidt, M.R., Kristiansen, S.B., Cheung, M., White, P.A., Sorensen, K. and Redington, A.N. (2002) Validation of Myocardial Acceleration During Isovolumic Contraction as a Novel Noninvasive Index of Right Ventricular Contractility: Comparison with Ventricular Pressure-Volume Relations in an Animal Model. Circulation, 105, 16931699. http://dx.doi.org/10.1161/01.CIR.0000013773.67850.BA

[4] Vogel, M., Derrick, G., White, P.A., Cullen, S., Aichner, H., Deanfield, J. and Redington, A.N. (2004) Systemic Ventricular Function in Patients with Transposition of the Great Arteries after Atrial Repair: A Tissue Doppler and Conductance Catheter Study. Journal of the American College of Cardiology, 43, 100-106. http://dx.doi.org/10.1016/j.jacc.2003.06.018

[5] Vogel, M., Cheung, M.M., Li, J., Kristiansen, S.B., Schmidt, M.R., White, P.A., Sorensen, K. and Redington, A.N. (2003) Noninvasive Assessment of Left Ventricular Force-Frequency Relationships Using Tissue Doppler-Derived Isovolumic Acceleration: Validation in an Animal Model. Circulation, 107, 1647-1652. http://dx.doi.org/10.1161/01.CIR.0000058171.62847.90

[6] Schattke, S., Knebel, F., Grohmann, A., Dreger, H., Kmezik, F., Riemekasten, G., Baumann, G. and Borges, A.C. (2010) Early Right Ventricular Systolic Dysfunction in Patients with Systemic Sclerosis without Pulmonary Hypertension: A Doppler Tissue and Speckle Tracking Echocardiography Study. Cardiovascular Ultrasound, 8, 3. http://dx.doi.org/10.1186/1476-7120-8-3

[7] Voelkel, N.F., Quaife, R.A., Leinwand, L.A., Barst, R.J., McGoon, M.D., Meldrum, D.R., Dupuis, J., Long, C.S., Rubin, L.J., Smart, F.W., Suzuki, Y.J., Gladwin, M., Denholm, E.M. and Gail, D.B. (2006) Right Ventricular Function and Failure: Report of a National Heart, Lung, and Blood Institute Working Group on Cellular and Molecular Mechanisms of Right Heart Failure. Circulation, 114, 1883-1891. http://dx.doi.org/10.1161/CIRCULATIONAHA.106.632208

[8] D’Alonzo, G.E., Barst, R.J., Ayres, S.M., Bergofsky, E.H., Brundage, B.H., Detre, K.M., Fishman, A.P., Goldring, 
R.M., Groves, B.M., Kernis, J.T. and et al. (1991) Survival in Patients with Primary Pulmonary Hypertension. Results from a National Prospective Registry. Annals of Internal Medicine, 115, 343-349. http://dx.doi.org/10.7326/0003-4819-115-5-343

[9] McLaughlin, V.V., Sitbon, O., Badesch, D.B., Barst, R.J., Black, C., Galie, N., Rainisio, M., Simonneau, G. and Rubin, L.J. (2005) Survival with First-Line Bosentan in Patients with Primary Pulmonary Hypertension. The European Respiratory Journal, 25, 244-249. http://dx.doi.org/10.1183/09031936.05.00054804

[10] Sandoval, J., Bauerle, O., Palomar, A., Gomez, A., Martinez-Guerra, M.L., Beltran, M. and Guerrero, M.L. (1994) Survival in Primary Pulmonary Hypertension. Validation of a Prognostic Equation. Circulation, 89, 1733-1744. http://dx.doi.org/10.1161/01.CIR.89.4.1733

[11] Rudski, L.G., Lai, W.W., Afilalo, J., Hua, L., Handschumacher, M.D., Chandrasekaran, K., Solomon, S.D., Louie, E.K. and Schiller, N. B. (2010) Guidelines for the Echocardiographic Assessment of the Right Heart in Adults: A Report from the American Society of Echocardiography Endorsed by the European Association of Echocardiography, a Registered Branch of the European Society of Cardiology, and the Canadian Society of Echocardiography. Journal of the American Society of Echocardiography: Official Publication of the American Society of Echocardiography, 23, 685-713. http://dx.doi.org/10.1016/j.echo.2010.05.010

[12] Toyono, M., Harada, K., Tamura, M., Yamamoto, F. and Takada, G. (2004) Myocardial Acceleration During Isovolumic Contraction as a New Index of Right Ventricular Contractile Function and Its Relation to Pulmonary Regurgitation in Patients after Repair of Tetralogy of Fallot. Journal of the American Society of Echocardiography: Official Publication of the American Society of Echocardiography, 17, 332-337. http://dx.doi.org/10.1016/j.echo.2003.12.022

[13] Arnold, R., Gorenflo, M., Bottler, P., Eichhorn, J., Jung, C. and Goebel, B. (2008) Tissue Doppler Derived Isovolumic Acceleration in Patients after Atrial Repair for Dextrotransposition of the Great Arteries. Echocardiography (Mount Kisco, N.Y.), 25, 732-738. http://dx.doi.org/10.1111/j.1540-8175.2008.00686.x

[14] Bayram, N.A., Ciftci, B., Bayram, H., Keles, T., Durmaz, T., Akcay, M., Yeter, E. and Bozkurt, E. (2008) Effects of Continuous Positive Airway Pressure Therapy on Right Ventricular Function Assessment by Tissue Doppler Imaging in Patients with Obstructive Sleep Apnea Syndrome. Echocardiography (Mount Kisco, N.Y.), 25, 1071-1078. http://dx.doi.org/10.1111/j.1540-8175.2008.00731.X

[15] Tayyareci, Y., Nisanci, Y., Umman, B., Oncul, A., Yurdakul, S., Altun, I., Umman, S. and Bugra, Z. (2008) Early Detection of Right Ventricular Systolic Dysfunction by Using Myocardial Acceleration During Isovolumic Contraction in Patients with Mitral Stenosis. European Journal of Echocardiography: The Journal of the Working Group on Echocardiography of the European Society of Cardiology, 9, 516-521. http://dx.doi.org/10.1016/j.euje.2007.08.007

[16] Vogel, M., Maedler, C., Williams, I., Deanfield, J. and Fraser, A. (2001) Myocardial Acceleration during Isovolumic Contraction: Effect of Age on Right and Left Ventricular Systolic Function in 225 Normals from Age 2 - 84 Years. Circulation, 104, 3536.

[17] Hashimoto, I., Li, X.K., Bhat, A.H., Jones, M. and Sahn, D.J. (2005) Quantitative Assessment of Regional Peak Myocardial Acceleration during Isovolumic Contraction and Relaxation Times by Tissue Doppler Imaging. Heart (British Cardiac Society), 91, 811-816. http://dx.doi.org/10.1136/hrt.2004.033845

[18] Dambrauskaite, V., Delcroix, M., Claus, P., Herbots, L., D’hooge, J., Bijnens, B., Rademakers, F. and Sutherland, G.R. (2007) Regional Right Ventricular Dysfunction in Chronic Pulmonary Hypertension. Journal of the American Society of Echocardiography, 20, 1172-1180. http://dx.doi.org/10.1016/j.echo.2007.02.005 
Scientific Research Publishing (SCIRP) is one of the largest Open Access journal publishers. It is currently publishing more than 200 open access, online, peer-reviewed journals covering a wide range of academic disciplines. SCIRP serves the worldwide academic communities and contributes to the progress and application of science with its publication.

Other selected journals from SCIRP are listed as below. Submit your manuscript to us via either submit@scirp.org or Online Submission Portal.
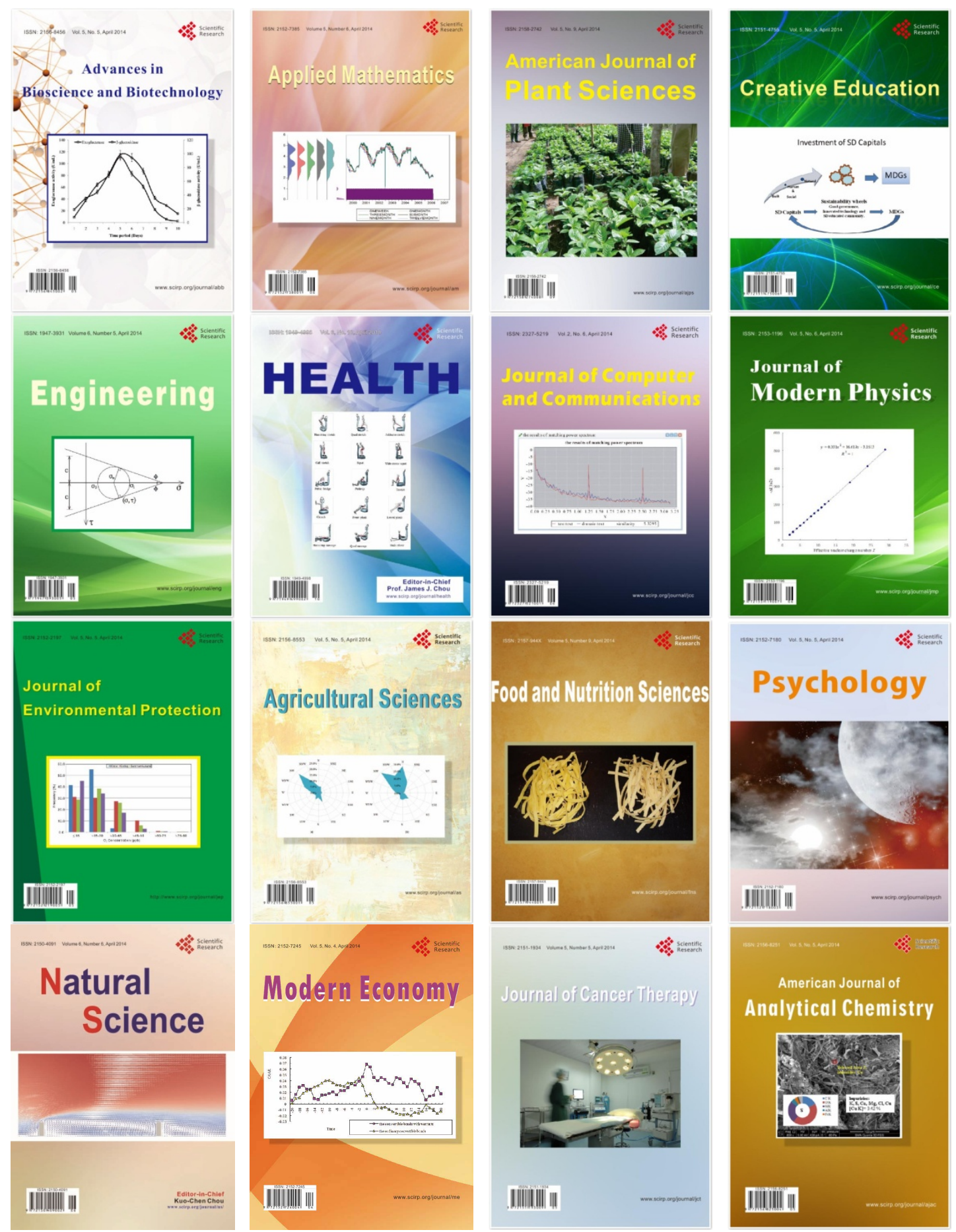